\title{
Using the Entropy Rate Balance to Determine the Heat Transfer and Work in an Internally Reversible, Polytropic, Steady State Flow Process
}

Savannah Griffin

University of South Florida

Advisors:

Arcadii Grinshpan, Mathematics and Statistics

Curtis Griffın, Fertilizer Technologies, PegasusTSI

Problem Suggested By: Savannah Griffin

Follow this and additional works at: https://digitalcommons.usf.edu/ujmm

Part of the Mathematics Commons

UJMM is an open access journal, free to authors and readers, and relies on your support: Donate Now

\section{Recommended Citation}

Griffin, Savannah (2018) "Using the Entropy Rate Balance to Determine the Heat Transfer and Work in an Internally Reversible, Polytropic, Steady State Flow Process," Undergraduate Journal of Mathematical Modeling: One + Two: Vol. 8: Iss. 2, Article 2. DOI: http://doi.org/10.5038/2326-3652.8.2.4889

Available at: https://digitalcommons.usf.edu/ujmm/vol8/iss2/2 


\title{
Using the Entropy Rate Balance to Determine the Heat Transfer and Work in an Internally Reversible, Polytropic, Steady State Flow Process
}

\author{
Abstract \\ The entropy rate equation for internally reversible steady state flow process has been used to calculate \\ the heat transfer and work in an internally reversible, polytropic, steady state flow process.

\section{Keywords} \\ polytropic, reversible process, entropy, heat transfer \\ Creative Commons License \\ (c) (i) (9) \\ This work is licensed under a Creative Commons Attribution-Noncommercial-Share Alike 4.0 License.
}




\section{PROBLEM STATEMENT}

Define and explain the entropy rate balance, derive and express the entropy rate balance equation as related to internally reversible, polytropic, steady state flow process and provide examples of how it can be applied.

\section{MOTIVATION}

Entropy is a thermodynamic property similar to temperature and pressure. It is a state function that changes during a reversible process in a closed system, and is related to the likelihood that equilibrium will be reached. The second law of thermodynamics states that the rate of entropy generation within a system must be greater than or equal to zero [1]. A process for which the rate of generation of entropy is always zero is a reversible process. A large rate of entropy generation corresponds to greater process irreversibilities [1].

\section{MATHEMATICAL DESCRIPTION AND SOLUTION APPROACH}

The entropy rate balance for controlled volumes is as follows [1]:

$$
\frac{d s_{c v}}{d t}=\sum \frac{Q}{T}+\sum m_{i} s_{i}-\sum m_{c} s_{c}+\sigma_{c v}
$$

Where $\frac{d s_{c v}}{d t}$ is the time rate of change of entropy within the control volume, the terms $m_{i} s_{i}$ and $m_{c} s_{c}$ account for the rates of entropy transferred in and out of the control volume with the accompanying mass flow. $Q$ represents the time rate of heat transfer at the location on the boundary where the instantaneous temperature is T. The ratio of $\frac{Q}{T}$ accounts for the accompanying rate of entropy transfer and the term $\sigma_{c v}$ denotes the time rate of entropy production due to the irreversibility's within the control volume [1]. At steady state the entropy rate balance of equation (1) reduces to the following equation: 


$$
0=\sum \frac{Q}{T}+\sum m_{i} s_{i}-\sum m_{c} s_{c}+\sigma_{c v}
$$

Since many applications involve one inlet and one outlet controlled volumes at steady state we can further simplify the rate balance equation (2) to get[1]:

$$
0=\frac{Q_{c v}}{T}+m\left(s_{1}-s_{2}\right)+\sigma_{c v}
$$

In equation (3) the subscript 1 indicates the inlet and the subscript 2 indicates the outlet.

For a control volume at steady state in which the flow is both isothermal and internally reversible, the rate of entropy production is zero and the entropy rate equation reduces further to: 0

$$
\begin{aligned}
& 0=\frac{Q_{c v}}{T}+m\left(s_{1}-s_{2}\right)+\sigma_{c v} \\
& 0=\frac{Q_{c v}}{T}+m\left(s_{1}-s_{2}\right)
\end{aligned}
$$

Rearranging equation (5) for the heat transfer per unit of mass passing through the control volume gives:

$$
\frac{Q_{c v}}{m}=T\left(s_{1}-s_{2}\right)
$$

The temperature varies as the gas or liquid flows through the controlled volume, and we can consider the temperature variation to consist of a series of small steps. This allows the heat transfer per unit mass to be given as in the following equation [1]:

$$
\left(\frac{Q_{c v}}{m}\right)=\int_{1}^{2} T d s
$$

This applies only to control volumes with no internal irreversibility's, the integral equation (7) is performed from the inlet to the exit and the heat transfer per unit mass flowing can be represented as the area under the curve. A T-s diagram can be used to show the area under the curve. 


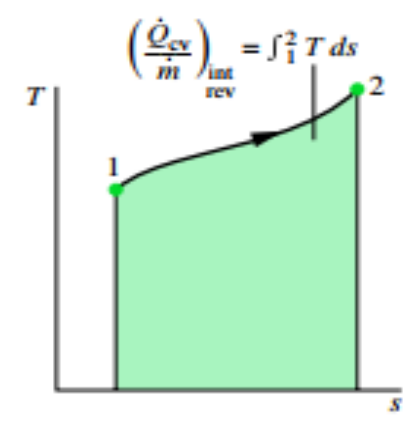

Figure 1: T-s diagram [1]

The work per unit mass passing through the controlled volume can be found from the energy rate balance at steady state to be:

$$
\frac{W_{c v}}{m}=\frac{Q_{c v}}{m}+\left(h_{1}+h_{2}\right)+\left(\frac{V_{1}^{2}-V_{2}^{2}}{2}\right)+g\left(z_{1}-z_{2}\right)
$$

where $W_{c v}$ is the work of the system, $h_{1}, h_{2}$ are the in and out enthalpy, respectively, of the system, $g$ is the force of gravity, $V_{1}, V_{2}$ are the in and out velocities, and $z_{1}, z_{2}$ are the heights, in and out. Equation (8) is obtained from the conservation principle of energy. It is valid when irreversibilities are present within the control volume as well as when they are absent [1]. If we are applying equation (8) to the internally reversible case we can modify the equation as follows:

$$
\frac{W_{c v}}{m}=\int_{1}^{2} T d s+\left(h_{1}+h_{2}\right)+\left(\frac{V_{1}^{2}-V_{2}^{2}}{2}\right)+g\left(z_{1}-z_{2}\right)
$$

Since internal irreversibilities are absent, a unit of mass transverses a sequence of equilibrium states as it passes from inlet to exit. Entropy, enthalpy and pressure changes are therefore related by the following in equation [4]:

Integration of equation (10) gives:

$$
T d s=d h-v d p
$$

$$
\int_{1}^{2} T d s=\left(h_{2}-h_{1}\right)-\int_{1}^{2} v d p
$$

Which can be rewritten using (10) as:

$$
\frac{W_{c v}}{m}=-\int_{1}^{2} v d p+\left(\frac{V_{1}^{2}-V_{2}^{2}}{2}\right)+g\left(z_{1}-z_{2}\right)
$$


When the states visited by a unit of mass as it passes from inlet to exit are described by a curve on a $\mathrm{p}-\mathrm{v}$ diagram, the magnitude of the integral $\int_{1}^{2} v d p$ is represented by the area below the curve as in Figure 2:

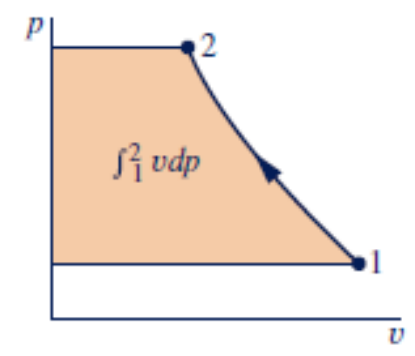

Figure 2: p-v diagram [1]

Equation (13) can be applied to study the performance of controlled volumes at steady state in which $\mathrm{W}$ is zero, for any such case the equation becomes a form of the Bernoulli equation [1]:

$$
0=\int_{1}^{2} v d p+\left(\frac{V_{1}^{2}-V_{2}^{2}}{2}\right)+g\left(z_{1}-z_{2}\right)
$$

The following equation can then be used for turbines, compressors and pumps when there is no significant change in kinetic or potential energy from inlet to exit $(\Delta k e=\Delta p e=0)$

$$
\frac{W_{c v}}{m}=-\int_{1}^{2} v d p
$$

This shows that the work is related to the magnitude of the specific volume of gas or liquid as it flows from inlet to exit. This can be rewritten as:

$$
\frac{W_{c v}}{m}=-v\left(p_{2}-p_{1}\right)
$$

Special forms of the entropy rate balance (i.e. equation (15)) result when the process is polytropic. A polytropic process is also called a quasiequilibium or quasistatic process. A polytropic process is one in which the departure from thermodynamic equilibrium is infinitesimal [4]. All states through which the system passes in a polytropic process may be considered equilibrium states. 


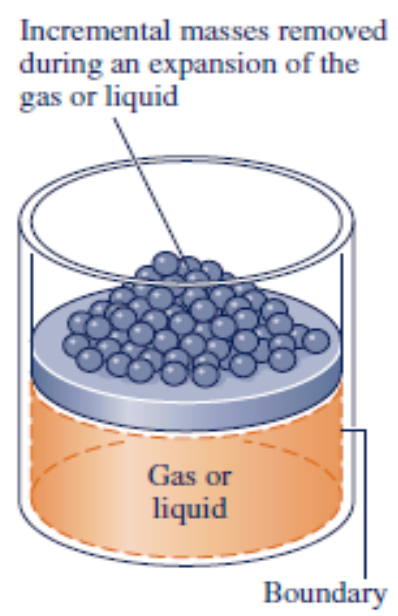

Figure 3: Polytropic state example [4]

A polytropic process can be described by the equation:

$$
p v^{n}=\text { constant }
$$

Inserting equation (16) into:

$$
\frac{W_{c v}}{m}=-\int_{1}^{2} v d p
$$

and performing an integration on (17) for $n \neq 1$ gives:

$$
\begin{aligned}
& \frac{W_{c v}}{m}=-\int_{1}^{2} v d p=- \text { constant }^{1 / n} \int_{1}^{2} \frac{d p}{p^{1 / n}} \\
& =\frac{n}{n-1}\left(p_{2} v_{2}-p_{1} v_{1}\right)
\end{aligned}
$$

If $n=1$ (19) becomes:

$$
\begin{aligned}
\frac{W_{c v}}{m}=-\int_{1}^{2} v d p & =- \text { constant } \int_{1}^{2} \frac{d p}{p} \\
& =p_{1} v_{1} \ln \frac{p_{2}}{p_{1}}
\end{aligned}
$$

As a special case of equation (20), when using an ideal gas, we have [3]:

We also know that [1]:

$$
\frac{W_{c v}}{m}=-\frac{n R}{n-1}\left(T_{2}-T_{1}\right)
$$

$$
\frac{T_{2}}{T_{1}}=\left(\frac{p_{2}}{p_{1}}\right)^{\frac{n-1}{n}}
$$


Substituting equation (22) in equation (21) and assuming $\mathrm{n} \neq 1$ gives:

$$
\frac{W_{c v}}{m}=\frac{n R T_{1}}{n-1}\left[\left(\frac{p_{2}}{p_{1}}\right)^{\frac{n-1}{n}}-1\right]
$$

If $\mathrm{n}=1$ we obtain:

$$
\frac{W_{c v}}{m}=-\mathrm{RT} \ln \left(\frac{p_{2}}{p_{1}}\right)
$$

These equations can now be used to solve problems associated with polytropic problems as in the Appendix.

\section{DISCUSSION}

The term "polytropic" was originally used to describe any reversible process on any open or closed system of gas or vapor which involves both heat and work transfer [4]. Typically a combination of properties are maintained constant throughout the process, also called the polytropic path. An ideal gas polytropic process is a thermodynamic process that obeys the relationship: $\mathrm{pV}^{\mathrm{n}}=\mathrm{C}$, where $\mathrm{p}$ is the

pressure, $\mathrm{V}$ is the volume, $\mathrm{n}$ is the polytropic index and $\mathrm{C}$ is a constant ${ }^{4}$. The polytropic process equation can describe multiple expansion and compression processes which include heat transfer. There are specific cases with particular values of $n$, for example; $n=0$ for a isobaric process, and $n=1$ when the ideal gas law applies for a isothermic process [1]. The value of $\mathrm{n}$ has an impact on the amount of work and heat transfer that is developed by the system. The value of $\mathrm{n}$ for other gas compression and expansion processes are typically determined experimentally by the measurement of the heat and work transferred at the initial and final states[1]. The entropy rate balance was used as a basis, and the entropy rate equation for internally reversible, polytropic, steady state flow process was derived. The entropy rate equation for internally reversible steady state flow process was then used to calculate the 
heat transfer and work for three specific examples. The ability to calculate the amount of work and heat transfer in a system is important in every day processes. Air compressors are used on a daily basis in numerous industries and the ability to understand the amount of heat transfer and work required to go from one state to another is important. Three examples of using a compressor at various pressures and temperatures while keeping the polytropic index constant were reviewed.

The results of the three examples are as follows:

\begin{tabular}{|l|c|c|c|c|c|c|c|}
\hline & $\begin{array}{c}\text { Pressure 1 } \\
\text { Bar }\end{array}$ & $\begin{array}{c}\text { Temperature 1 } \\
\text { C }\end{array}$ & $\begin{array}{c}\text { Pressure 2 } \\
\text { Bar }\end{array}$ & $\begin{array}{c}\text { Temperature 2 } \\
\mathrm{C}\end{array}$ & $\mathrm{n}$ & $\begin{array}{c}\text { Work } \\
\mathrm{kJ} / \mathrm{kg}\end{array}$ & $\begin{array}{c}\text { Heat } \\
\text { Transfer } \\
\mathrm{kJ} / \mathrm{kg}\end{array}$ \\
\hline Example 1 & 1 & 20 & 5 & 151.8 & 1.3 & -164.2 & -31 \\
\hline Example 2 & 1 & 40 & 10 & 257.8 & 1.3 & -271.0 & -50 \\
\hline Example 3 & 1 & 50 & 15 & 328.8 & 1.3 & -346.7 & -60 \\
\hline
\end{tabular}

The results came out as expected, showing that as the pressure in state 1 stayed constant with temperature 1, pressure 2 and temperature 2 increasing the work and heat transfer increase in the negative direction. This is mainly due to the entropy values that change as the temperature and pressure change. The results follow the entropy rate equation for a polytropic process as predicted. The results confirm that the objective of the project has been completed and verified.

\section{CONCLUSION AND RECOMMENDATIONS}

The entropy rate balance was used as a basis and using advanced calculus techniques the entropy rate equation for internally reversible, polytropic, steady state flow process was derived. The entropy rate equation for internally reversible steady state flow process was then used to calculate the heat transfer and work in an internally reversible, polytropic, steady state flow process. Three examples were used to show the impact on the work and heat transfer for various input values. The results of the 
three examples are as follows:

\begin{tabular}{|l|c|c|c|c|c|c|c|}
\hline & $\begin{array}{c}\text { Pressure 1 } \\
\text { Bar }\end{array}$ & $\begin{array}{c}\text { Temperature 1 } \\
\text { C }\end{array}$ & $\begin{array}{c}\text { Pressure 2 } \\
\text { Bar }\end{array}$ & $\begin{array}{c}\text { Temperature 2 } \\
\mathrm{C}\end{array}$ & $\mathrm{n}$ & $\begin{array}{c}\text { Work } \\
\mathrm{kJ} / \mathrm{kg}\end{array}$ & $\begin{array}{c}\text { Heat } \\
\text { Transfer } \\
\mathrm{kJ} / \mathrm{kg}\end{array}$ \\
\hline Example 1 & 1 & 20 & 5 & 151.8 & 1.3 & -164.2 & -31 \\
\hline Example 2 & 1 & 40 & 10 & 257.8 & 1.3 & -271.0 & -50 \\
\hline Example 3 & 1 & 50 & 15 & 328.8 & 1.3 & -346.7 & -60 \\
\hline
\end{tabular}

The results came out as expected showing that as the pressure in state 1 stayed constant with

temperature 1, pressure 2 and temperature 2 increasing the work and heat transfer increase in the negative direction. This is mainly due to the entropy values that change as the temperature and pressure change. The results follow the entropy rate equation for a polytropic process as predicted. A recommendation would be to further investigate the impact of the polytropic index on the impact on the work and heat transfer to the system. Various values can be used for the polytropic index and the correlated work and heat transfer values can be compared. This would allow a further understanding of the impact from the polytropic index.

\section{NOMENCLATURE}

\begin{tabular}{|c|c|c|}
\hline Symbol & Description & Unit \\
\hline $\mathrm{R}$ & $\begin{array}{c}\text { Ideal Gas } \\
\text { Constant }(8.314)\end{array}$ & $\mathrm{J} / \mathrm{mol} \mathrm{K}$ \\
\hline $\mathrm{T}$ & Temperature & $\mathrm{C}$ \\
\hline $\mathrm{W}_{\mathrm{cv}}$ & Work & $\mathrm{kJ} / \mathrm{kg}$ \\
\hline $\mathrm{p}$ & Pressure & $\mathrm{Bar}$ \\
\hline $\mathrm{n}$ & moles & $\mathrm{mol}$ \\
\hline $\mathrm{m}$ & Mass & $\mathrm{Kg}$ \\
\hline $\mathrm{z}$ & Height & $\mathrm{m}$ \\
\hline $\mathrm{g}$ & $\begin{array}{c}\text { Gravitational } \\
\text { Constant }\end{array}$ & $32.17 \mathrm{~m} / \mathrm{s}^{2}$ \\
\hline $\mathrm{V}$ & Velocity & $\mathrm{m} / \mathrm{sec}$ \\
\hline $\mathrm{h}$ & Entropy & $\mathrm{kJ} / \mathrm{kg}$ \\
\hline $\mathrm{Q}$ & Heat transfer & $\mathrm{kJ} / \mathrm{kg}$ \\
\hline $\mathrm{s}$ & Distance & $\mathrm{m}$ \\
\hline$\sigma_{c v}$ & Rate of entropy & $\mathrm{kJ} / \mathrm{kg}$ \\
\hline
\end{tabular}




\begin{tabular}{|c|c|c|}
\hline & production & \\
\hline$v$ & Volume & $\mathrm{m}^{3}$ \\
\hline
\end{tabular}

\section{REFERENCES}

[1] Moran, Michael Shapiro, Howard Fundamentals of Engineering Thermodynamics. Wiley and Sons, 246-249.

[2] Curtis Griffin, Interview.

[3] Arcadii Grinshpan, review of draft and feedback regarding project.

[4] Anderson, J. D., Modern Compressible Flow, With Historical Perspective, $2^{\text {nd }}$ edition (McGrawHill, Boston, 1990).

[5] Çengel, Y., Boles, Michael A., Thermodynamics: An Engineering Approach, $2^{\text {nd }}$ edition (McGrawHill, New York, 1994).

[6] Christians, Joseph (January 2012). "Approach for Teaching Polytropic Processes Based on the Energy Transfer Ratio". Int. J. Mech. Eng. Ed. Manchester University Press. 40 (1).

[7] Horedt, G. P. (2004-08-10). Polytropes: Applications In Astrophysics And Related Fields. Springer. p. 24 .

\section{APPENDIX}

EXAMPLE 1

An air compressor operates at steady state with air entering at $P_{1}=1$ bar, $T_{1}=20 \mathrm{C}$ and exiting at $P_{1}=$ 5 bar. Determine the work and heat transfer per unit of mass passing through the device, in $\mathrm{Kg} / \mathrm{KJ}$, if the air undergoes a polytropic process with $n=1.3$. Neglect changes in kinetic and

potential energy between the inlet and exit [1].

\section{Assumptions}

The volume is at steady state. 
The air is polytropic with $n=1.3$.

The air acts as ideal gas.

Changes in kinetic and potential energy are neglected.

Solution

Find the temperature at the exit

$$
\begin{gathered}
T_{2=} T_{1}\left(\frac{P_{2}}{P_{1}}\right)^{\frac{n-1}{n}} \\
T_{2}=293\left(\frac{5}{1}\right)^{\frac{1.3-1}{1.3}} \\
T_{2}=425 \mathrm{~K}
\end{gathered}
$$

Finding the work using the following equation:

Substituting we find:

$$
\frac{W_{c v}}{m}=\frac{n R}{n-1}\left(T_{2}-T_{1}\right)
$$

$$
-\frac{W_{c v}}{m}=\frac{1.3}{1.3-1}(425 K-293 K)\left(\frac{8.314}{28.97}\right)=-164.2 \mathrm{kj} / \mathrm{kg}
$$

The heat transfer can now be found using the following equation:

$$
\frac{Q_{c v}}{m}=\frac{W_{c v}}{m}+h_{2}-h_{1}=-164.2+(426.35-293.17)=-31 \mathrm{kj} / \mathrm{kg}
$$

Where $h_{2}$ and $h_{1}$ are obtained from the entropy table at the specific temperature. 